\title{
ESTIMATION OF OXIDATIVE STABILITY OF THE LIPID COMPLEX OF CREAMY-SHAKEN CANDIES WITH CHIA SEEDS AT STORAGE
}

\author{
Olena Shydakova-Kameniuka \\ shidakovae@gmail.com \\ Oleksii Shkliaiev \\ Superlakomka LLC \\ 29 Kashtanovaya str., Kharkiv, Ukraine, 61124 \\ Olga Samokhvalova ${ }^{1}$ \\ Maya Artamonova ${ }^{1}$ \\ Galyna Stepankova \\ Department of Processing and Food Production Technologies \\ Kharkiv Petro Vasylenko National Technical University of Agricalture \\ 92 Mironosytska str., Kharkiv, Ukraine, 61023 \\ Olena Bolkhovitina ${ }^{1}$ \\ Alla Rogova \\ Department of food industry technologies and restaurant industry \\ Poltava University of Economics and Trade \\ 3 Kowalja str., Poltava, Ukraine, 36014 \\ ${ }^{1}$ Department of Bakery, Confectionary, Pasta and Food Concentrates Technology \\ Kharkiv State University of Food Technology and Trade \\ 333 Klochkivska str., Kharkiv, Ukraine, 61051
}

\begin{abstract}
One of ways of developing the confectionary industry is a search for raw material resources with a high content of nutrients, useful for the human organism. A promising type of such raw materials is non-traditional oil seeds, especially chia seeds. The aim of the study was to estimate the oxidative stability of the lipid complex of creamy-shaken candies with chia seeds at storage. It is noted, that lipase of chia seeds doesn't manifest activity in an acid medium. That is why chia seeds introduction to creamy-shaken candies (with $\mathrm{pH}<6,0$ ) doesn't accelerate hydrolytic disintegration of their lipid component at storage. A type of jelly-former, used at candy production (agar-agar, pectin, modified starch), doesn't influence the accumulation dynamics of free fatty acids in candies. It is noted, that the lipid component of creamy-shaken candies, produced with agar-agar and pectin, is characterized with the equal dynamics of a peroxide value. The accumulation of peroxide compounds in starch products takes place slower. It has been established, that despite the high content of polyunsaturated fatty acids, the lipid component of candies with chia seeds comparing with control is characterized by less inclination to oxidation. It is noted, that at the $30^{\text {th }}$ day of storage relative changes of peroxide value indices of products with supplements are 1.00 and 0.81 against 1.85 and 1.49 in control samples on agar-agar (pectin) and starch respectively. The braking effect of chia seeds on oxidizing processes is conditioned by the high content of tocopherols and phenol compounds (quercetin, coffee, chlorogenic acids, rutin, polyphenol compounds) with antioxidant properties in them.

It has been established, that during the studied storage term products didn't gain a rancid smack, testifying to the accumulation of secondary oxidation processes. The structure and color of the studied samples of candies didn't also change. That is during the normative storage term (60 days) creamy-shaken candies with chia seeds correspond to normative requirements by organoleptic parameters and quality ones of the lipid complex.
\end{abstract}

Keywords: chia seeds, hydrolysis of lipids, oxidation of lipids, lipase, lipoxygenase, creamy-shaken candies, storage. 


\section{Introduction}

Modern world tendencies of the confectionary industry development are mainly oriented on creation of products, healthy for humans. Taking it into account, today producers accent attention on using raw materials, including physiologically healthy nutrients: polyunsaturated fatty acids, mineral substances, vitamins, phenol compounds, soluble and insoluble dietary fiber and so on at making confectionary products [1]. An essential amount of such substances is contained in vegetable raw materials, especially in oil seeds.

Main types of oil seeds, used today in confectionary technologies, are sunflower, flax, sesame, amaranth, rape and so on. Seeds are introduced whole and comminuted as flour (fatty or fatless), by-products of oil production (meals, oilcake).

These raw materials are most widely used in technologies of floury confectionary products. Rape meal (25\% of the flour mass) [2, 3], flax and sesame meal (12..20\% of the flour mass) [4, 5], whole seeds of sunflower or flax $(10 \ldots 13 \%$ to the flour mass) $[6,7]$, sunflower flour (up to $17 \%$ of the flour mass) [8] and so on are known for using for this product. Oils seeds are also used in confectionary technologies. There is offered a base for fat-containing candy masses, including comminuted sunflower (12\%), sesame (18\%) and flax (30\%) seeds [9]. Recommendations about using amaranth flour at producing pomade masses (10\% of the sugar mass) are given [10].

The given information testifies that the introduction of oil seeds and their processing products to these technologies is realized in rather high concentrations. That is the enrichment of products with physiologically healthy nutrients will be essential. Especially, the use of fatless products of oil seeds (meals, oilcakes, flour) allows to enrich products mainly by proteins (in 1.3 ..2.4 times) and dietary fiber (in 4 times and more) $[4,5,8,10]$. At using native whole or comminuted seeds, the content of polyunsaturated fatty acids in products additionally rises (in 2 times and more $[6,7,9]$. It is known, that these nutrients strengthen protective functions of the human organism, favor normalization of cholesterol metabolism, prevent the development of cardiovascular diseases and so on. But fats, containing the essential amount of acyls of unsaturated acids, are easily oxidized under the influence of technological factors and in the process of storage, creating peroxide radicals. These compounds disintegrate, creating secondary oxidation products (aldehydes, ketones), giving fat a rancid smack. The presence of lipase and lipoxygenase that activate processes of hydrolytic and oxidizing spoilage of fats is typical for all types of oil seeds. So, at using native oil seeds in confectionary technologies, it is necessary to control the oxidative stability of the lipid component of a product at storage.

Chia seed is today a popular super-product that is conditioned by the wide spectrum of its healthy properties. It is proved, that regular consumption of these seeds prevents the development of autoimmune and cardiovascular diseases, has the anti-inflammatory, hepatoprotective and anti-diabetic effect [12]. A special feature of its chemical composition is the high content of polyunsaturated fatty acids - near $80 \%$ of all lipids [13], easily subjected to oxidation under the effect of technological factors and enzymes as it was noted above. It is known, that inactivation of enzymes takes place at temperature higher $65^{\circ} \mathrm{C}$ [14]. Stages of the technological process of producing creamy-shaken candies, at which chia seeds are introduced, don’t provide such temperature regimes. That is enzymes of the supplement remain active.

Taking it into account, the aim of the study was to estimate the oxidative stability of the lipid complex of creamy-shaken candies with chia seeds at storage. It allows to determine the correspondence of new products to the regulated storage terms.

It was necessary to carry out the complex of interconnected tasks for attaining the set aim:

- to study the activity of lipase and lipoxygenase in chia seeds;

- to estimate changes of acid and peroxide values of the fat fraction of creamy-shaken candies with chia seeds at storage;

- to estimate organoleptic characteristics of candies with chia seeds at storage.

\section{Materials and methods}

\section{1. Research materials}

The research subject was chosen as creamy-shaken candies. As raw materials for producing candies, there were used: white sugar (SSU 4623:2006); starch treacle (SSU 4498:2005); food agar- 
agar (SSU 16280-88); lemon acid (SSU 908-2006); dry egg albumin (SSU 2212:2003); apple pectin SWEJ-1 (SSU 6088: 2009), modified oxidized jellying starch OPV-1 (SSU 4380:2005 ), food aromatic essences (SSU 4716:2007); drinking water (SSU 2874-82); fatty condensed milk with sugar (SSU 4274:2003); margarine (SSU 4498:2005); chia seeds (TC U 15.8-31062161-010:2008). Used chia seeds were from harvest 2018, imported by PE "SPC "Sigma" (Ukraine), country of origin Bolivia. Seeds were introduced whole and comminuted (Fig. 1).





$b$

Fig. 1. Photo image of chia seeds: $a$-whole; $b$-comminuted

The study included samples of creamy-shaken candies, produced using different jellyformers:

- creamy-shaken candies without a supplement on agar-agar;

- creamy-shaken candies with chia seeds on agar-agar;

- creamy-shaken candies without a supplement on pectin;

- creamy-shaken candies with chia seeds on pectin;

- creamy-shaken candies without a supplement on modified starch;

- creamy-shaken candies with chia seeds on modified starch.

\section{2. Method of preparing candy samples for studying}

Dry egg albumin was combined with water (1:7) and left for hydration for $10 \mathrm{~min}$. The albumin solution was introduced with whole chia seeds in amount $40 \%$ of the albumin mass and left for $10 \mathrm{~min}$ for swelling. The obtained mixture was shaken during $20 \mathrm{~min}$. The prepared protein mass was shaken during $12 \pm 2 \mathrm{~min}$ with syrup, cooled to temperature $65 \pm 2{ }^{\circ} \mathrm{C}$. Syrup was made by boiling sugar, treacle and jelly-former (agar-agar, pectin or modified starch). Margarine with condensed milk and comminuted chia seeds were shaken separately. The dosage of comminuted seeds was $40 \%$ of the margarine mass. The shaken protein mass was combined with the fat mixture and formed by smearing. The structure was created at temperature $19 . .21^{\circ} \mathrm{C}$ during $60 \mathrm{~min}$. The structured candy mass was cut in pieces and glazed by chocolate.

The candy samples were stored under standard conditions (temperature $20 \pm 2{ }^{\circ} \mathrm{C}$ ) in a polyethylene film during the normative term - 60 days. Samples for the analysis were taken each 10 days.

\section{3. Methods of studying the activity of lipases and lipoxygenases in chia seeds}

Reagents for the study were prepared according to [15].

\section{3. 1. Method of studying lipase activity}

The activity of acid and alkaline lipases was studied. Acid lipase manifests activity in the medium with $\mathrm{pH}$ 4.7...5.0, alkaline - in the medium with $\mathrm{pH}$ 8.0..8.4. So, the method of their determination is based on titration of fatty acids, formed under the effect of enzyme on fat in the light-acid or alkaline medium by the alkaline solution. 
Batches of comminuted seeds of $2.50 \pm 0.01 \mathrm{~g}$ were accurately rubbed in a pestle with $1 \mathrm{~cm}^{3}$ of refined sunflower oil. The rubbed mass was put in conic flasks of $100 \mathrm{~cm}^{3}$, its residues from the pestle were washed away by $5 \mathrm{~cm}^{3}$ of distilled water. 5 drops of toluol were added, accurately mixed, corked and thermostated during 20 hours at temperature $30{ }^{\circ} \mathrm{C}$. After ending of thermostating the flasks were poured by $50 \mathrm{~cm}^{3}$ of the mixture of ethyl alcohol and ether (4:1). The mixture was precipitated and titrated by the solution of potassium hydroxide $\left(0.1 \mathrm{~mol} / \mathrm{dm}^{3}\right)$ with $0.5 \mathrm{~cm}^{3}$ of thymolphthalein. For control samples, there were also taken 2 batches of comminuted seeds (of $2.50 \pm 0.01 \mathrm{~g}$ ) and the same actions, excluding thermosating, were conducted with them.

The lipase enzyme activity $\left(\mathrm{AL}, \mathrm{cm}^{3} / \mathrm{g}\right)$ was calculated by the formula

$$
A L=\frac{(a-b) k}{m},
$$

where $a$-amount of $0,1 \mathrm{~mol} / \mathrm{dm}^{3}$ of the potassium hydroxide solution, spent for titrating the studied sample, $\mathrm{cm}^{3} ; b$ - the same for the control sample; $k$ - correcting coefficient to $0.1 \mathrm{~mol} / \mathrm{dm}^{3}$ of the potassium hydroxide solution, $k=1 ; m-$ fat batch, $g$.

\section{3. 2. Method for studying the lipoxygenase activity}

The method for determining the lipoxygenase activity is based on determining a peroxide value, changing in the process of absorbing molecular oxygen by the substrate and is accompanied by hydroperoxides formation under the effect of the enzyme. Sunflower oil was used as a substrate. The reactionary mixture was formed of the solution of the enzyme, phosphate-citrate buffer ( $\mathrm{pH}$ 7.0) and substrate. Distilled water was used in the control sample instead of the enzyme. The peroxide value was determined in the experimental and control samples. The research method is presented in detail in [16].

\section{4. Method of removing fat from candies}

Fat was removed from candies by the extraction method. The batch of candies $(300 \ldots 350 \mathrm{~g})$, was released from glaze, comminuted and put to a conic flask with microsections. The comminuted mass was poured with chloroform (1:2), infused for 24 hours without a light access and filtered. All further analyzes were conducted with this extract. The amount of fat, transferred to the extract, was determined by the difference of the mass of $1 \mathrm{ml}$ of the extract before and after drying. Drying was conducted in a drying chamber at temperature $105^{\circ} \mathrm{C}$ up to the constant mass.

\section{5. Methods of studying the acid and peroxide value of fat}

For determining the acid and peroxide values, there was taken the extract amount with the necessary fat amount. Then PV (Peroxide value) and AV (Acid Value) were determined by standard methods [17]. PV was expressed in $\mathrm{mmol} 1 / 2 \mathrm{O} / \mathrm{kg}$, and $\mathrm{AV}$ - in $\mathrm{mg} \mathrm{KOH} / \mathrm{g}$ of the sample.

The dynamics of peroxides accumulation in the process of storage was estimated by the index of the peroxide value relative change $\delta \mathrm{PV}$, calculated according to [18] by the formula

$$
\delta P V=\frac{P V_{t}-P V_{0}}{P V_{0}},
$$

where $P V_{t}, P V_{0}$ - peroxide values of the samples, corresponding to the storage term $t$ days and initial condition.

\section{6. Method of estimating organoleptic characteristics of candies}

Organoleptic parameters of candies were controlled immediately after preparing and after storage ending (in 60 days). The estimation was conducted according to SSU 4683:2006 by the parameters: color, structure, smell and taste. 


\section{7. Statistical processing of the results}

The statistical processing of the experimental results was carried out using standard packages of programs Microsoft Office for a series of parallel measurements $(n=4-5, p<0,05)$.

\section{Research results of the activity of chia seed enzymes and the condition of the lipid complex of candies with it}

\section{1. Study of the lipase and lipoxygenase activity in chia seeds}

The lipase and lipoxygenase activity in chia seeds was analyzed comparing with one in other types of oil seeds (Table 1).

\section{Table 1}

The lipase and lipoxygenase activity in chia seeds comparing with one in other types of oil seeds $(p<0.05$, $n=4, \sigma=3,5 \ldots 4.0 \%)$

\begin{tabular}{lccc}
\hline \multirow{2}{*}{ Enzyme } & \multicolumn{3}{c}{ Enzyme activity } \\
\cline { 2 - 4 } & Chia seeds & Sunflower seeds [19] & Sesame seeds [20 \\
\hline Lipase, $\mathrm{cm}^{3} / \mathrm{g}$ & & & inactive \\
acid & inactive & $1.45 \ldots .2 .28$ & 0.56 \\
alkaline & 1.70 & $0.33 \ldots 0.40$ & 1.42 \\
Lipoxygenase, $\mathrm{mmol}^{1 / 2} \mathrm{O} / \mathrm{kg}$ & 2.06 & $2.0 \ldots 3.3$
\end{tabular}

It is noted, that acid lipase of both chia seeds and sesame ones doesn't manifest activity. Whereas, its activity is rather high for sunflower seeds. However chia is characterized with the higher activity of alkaline lipase comparing with other seeds. That is it may be foreseen, that introduction of chia seeds to food systems with an acid medium must not initiate hydrolytic disintegration of lipids. The absence of hydrolysis products in a fat system in its turn prevents the lipoxygenase effect. It is conditioned by the fact that free fatty acids, formed at the expanse of lipase effect, are faster oxidized by lipoxygenase than ones, bound with an acyl glycerin molecule. It is noted, that the activity of chia seed lipoxygenase is at the level of other types of oil seeds.

\section{2. Study of acid and peroxide values of fat}

An oxidation degree of the lipid component of creamy-shaken candies with chia seeds was estimated by the acid (Table 2) and peroxide (Fig. 1) values.

Table 2

Acid value $A V, \mathrm{mg} \mathrm{KOH}$ of lipids in the studied samples $(p<0,05, n=5, \sigma=3.5 \ldots 4.0 \%)$

\begin{tabular}{cccccccccc}
\hline & \multirow{2}{*}{ Sample } & \multicolumn{7}{c}{ Storage duration, days } \\
\cline { 3 - 9 } & & & $\mathbf{0}$ & $\mathbf{1 0}$ & $\mathbf{2 0}$ & $\mathbf{3 0}$ & $\mathbf{4 0}$ & $\mathbf{5 0}$ & $\mathbf{6 0}$ \\
\hline \multirow{2}{*}{ On agar-agar } & Control & 1.11 & 1.17 & 1.26 & 1.37 & 1.5 & 1.61 & 1.69 \\
& With chia seeds & 1.16 & 1.22 & 1.29 & 1.41 & 1.55 & 1.67 & 1.75 \\
\multirow{2}{*}{ On pectin } & Control & 1.13 & 1.19 & 1.27 & 1.38 & 1.52 & 1.63 & 1.71 \\
& With chia seeds & 1.18 & 1.23 & 1.31 & 1.43 & 1.58 & 1.7 & 1.8 \\
\multirow{2}{*}{ On modified starch } & Control & 1.10 & 1.15 & 1.24 & 1.35 & 1.49 & 1.6 & 1.68 \\
& With chia seeds & 1.14 & 1.21 & 1.28 & 1.39 & 1.53 & 1.64 & 1.73
\end{tabular}

The index of peroxide value characterizes the presence of free fatty acids, formed as a result of hydrolysis of acyl glycerins, accelerated with a temperature increase and under the 
effect of enzymes, in lipids. It is known [14], that hydrolytic enzymes of oil seeds are activated at comminution, medium humidity increase higher $12 \%$ and in temperature interval $30 \ldots 50{ }^{\circ} \mathrm{C}$. According to the developed technology, there are used whole and comminuted chia seeds. Whole chia seeds are introduced at the stage of protein mass shaking, further boiled by syrup with temperature $65 \pm 2{ }^{\circ} \mathrm{C}$. This temperature is not enough for inactivating enzymes. At the same time the obtained semi-product is characterized by high humidity $(22.0 \pm 2.0 \%)$, and is also favorable for the enzymatic activity. Introduction of comminuted seeds is realized at the stage of plasticized margarine shaking (temperature $37 \pm 2{ }^{\circ} \mathrm{C}$ ) with condensed milk (temperature $20 \pm 2{ }^{\circ} \mathrm{C}$ ). The temperature, comminution and humidity $(16.0 \pm 2.0 \%)$ also cause enzymes activation. Taking it into account, the samples of creamy-shaken candies after preparation are characterized by a bit higher acid value comparing with the control samples (Table 2). But in the process of storage the speed of hydrolytic processes in the control and experimental samples is almost equal. Especially, the increase of $A V$ in the lipid complex of candies without a supplement in 60 days of storage is $1.51 \ldots 1.53$ times and in ones with chia seeds $-1.50 \ldots 1.52$ times. It may be explained by the fact that lemon acid is introduced at the final stage of preparing the creamy-shaken candy mass. As a result, the obtained mass has an acid medium $(\mathrm{pH}<6.0)$. As it is testified by the research results of the activity of hydrolytic enzyme of chia seeds (Table 1), its lipase in the acid medium doesn't manifest activity. Taking it into account, enzymatic hydrolysis of the lipid component of candies with chia seeds doesn't take place at storage. It is noted, that during the whole storage period the studied samples of candies correspond to the requirements of normative documents by the acid value - don't exceed $2 \mathrm{mg} \mathrm{KOH} / \mathrm{g}$.

An oxidation degree of lipids is determined by the peroxide value. It is noted, that the lipid component of creamy-shaken candies, prepared on agar-agar and pectin, is characterized with the equal dynamics of this parameter change (Fig. 2, a). It is conditioned by the fact that their recipe composition differs only by the type of jelly-former. Creamy-shaken candies, based on modified starch, are characterized with the lower content of fat in the recipe; as a result the dosage of chia seeds in them is also lower. At the same time candies, based on starch, are characterized with more density- $0.920 \ldots 0.960 \mathrm{~g} / \mathrm{cm}^{3}$ against $0.600 \ldots 0.620 \mathrm{~g} / \mathrm{cm}^{3}$ in candies on pectin or agar. Taking it into account, their structure is less aired that is a probability of contacts between fat molecules with oxygen decreases. That is why the accumulation of peroxide compounds in the lipid component of candies on starch is slower (Fig. 2, b, Table 3).



$a$



$b$

Fig. 2. Changes of peroxide values of the lipid component of the studied samples of creamy-shaken candies at storage: $a$ - candies, prepared on agar-agar or pectin; $b$ - candies, prepared on modified starch $(p<0.05, n=5, \sigma=4.0 \ldots 4.3 \%)$ 
The research results (Fig. 2, Table 3) testify that despite the high content of polyunsaturated fatty acids, the lipid component of candies with chia seeds is characterized with less inclination to oxidation comparing with the control. Especially, it is noted, that at $30^{\text {th }}$ day of storage relative changes of the peroxide value of the products with the supplements are 1.00 and 0.81 against 1.85 and 1.49 in the control samples on agar-agar (or pectin) and starch respectively (Table 3). It is noted, that the peroxide accumulation speed in the control samples at the $60^{\text {th }}$ day becomes a bit slower. Especially, the peroxide value in lipids of candies on agaragar (or pectin) and starch in the period from the $40^{\text {th }}$ to $50^{\text {th }}$ day rises by $33.8 \%$ and $37.6 \%$ respectively. And for the period $50^{\text {th }}-60^{\text {th }}$ day the peroxide value of these samples rises only by 8.1 and $11.9 \%$. It testifies to the fact that in 50 days of storage peroxide compounds become to disintegrate, creating secondary oxidation products. This tendency is less expressed for the samples of candies with chia seeds. Especially, from $40^{\text {th }}$ to $50^{\text {th }}$ day the content of peroxides in the lipid fraction of candies with the supplement on agar-agar (or pectin) rises by $37.18 \%$, and in the following 10 days - by $14.7 \%$. The increase of the peroxide content in these periods for candies on starch is $43.2 \%$ and $14.36 \%$ respectively. The braking influence of chia seeds on oxidation processes of the lipid component of creamy-shaken candies may be explained by the high content of phenol compounds with antioxidant properties in them. It is known, that chia seeds contain quercetin, coffee, chlorogenic acids, rutin, polyphenol compounds [21]. The high antioxidant activity of phenol compounds of chia seeds is confirmed by researches [22]. The abovementioned antioxidants are water-soluble. Their effectiveness as to braking fat oxidation is conditioned by the following. Creamy-shaken candy masses are polydispersed systems, including an emulsion component. An antioxidant, solved in the dispersed medium, covers the emulsion phases' distribution surface. It provides its maximal contact with a lipid phase and allows to bind peroxide radicals. Chia seeds also contain the essential amount of tocopherols $(1.48 \mathrm{mg} / 100 \mathrm{~g}$ [12]), solving in the fat medium and inhibiting creation of lipid radicals directly in the fat component.

Table 3

Relative change of the peroxide value $\delta \mathrm{PV}$ of the lipid component of the studied samples at storage (relative to the first day)

\begin{tabular}{lcccccccc}
\hline \multirow{2}{*}{ Sample } & \multicolumn{5}{c}{ Storage term, days } \\
\cline { 3 - 8 } & & $\mathbf{1 0}$ & $\mathbf{2 0}$ & $\mathbf{3 0}$ & $\mathbf{4 0}$ & $\mathbf{5 0}$ & $\mathbf{6 0}$ \\
\hline \multirow{2}{*}{ On agar-agar or pectin } & Control & 0.35 & 0.85 & 1.85 & 3.16 & 4.57 & 5.02 \\
& With chia seeds & 0.18 & 0.42 & 1.00 & 2.26 & 3.47 & 4.13 \\
\multirow{2}{*}{ On modified starch } & Control & 0.32 & 0.68 & 1.49 & 2.85 & 4.30 & 4.94 \\
& With chia seeds & 0.10 & 0.34 & 0.81 & 1.93 & 3.19 & 3.80
\end{tabular}

The peroxide value index must not exceed $10 \mathrm{mmol} 1 / 2 \mathrm{O} / \mathrm{kg}$ for high-quality fatty systems. It has been established, that fat fractions of all studied samples of candies correspond to these requirements.

\section{3. Study of organoleptic characteristics of candies}

It is known, that peroxide compounds disintegrate with creation of secondary oxidation products (aldehydes, ketons and so on) that cause a rancid smack in fat-containing products. But the analysis of quality characteristics and organoleptic parameters of the studied samples of candies demonstrated that in 60 days of storage none product get rancid signs. The structure of products and color also don't change at storage.

That is during the regulated storage term (60 days) creamy-shaken candies with chia seeds correspond to the normative requirements by quality parameters and organoleptic characteristics of the lipid complex. 


\section{Conclusions}

It is noted, that lipase of chia seeds doesn't manifest activity in the acid medium. That is why their introduction to creamy-shaken candies doesn't accelerate hydrolytic disintegration of its lipid component at storage. A type of jelly-former, used at preparing candies (agar-agar, pectin, modified starch, doesn't influence the accumulation dynamics of free fatty acids in candies.

It is noted, that the lipid component of creamy-shaken candies, produced with agar-agar and pectin, is characterized with the equal dynamics of a peroxide value. The accumulation of peroxide compounds in starch products takes place slower (at the expanse of less mass aeration). The braking effect of chia seeds on oxidizing processes is conditioned by the high content of tocopherols and phenol compounds with antioxidant properties in them.

It has been established, that during the studied storage term products didn't gain a rancid smack, testifying to the accumulation of secondary oxidation processes. The structure and color of the studies samples of candies didn't also change.

The research results allow to make a conclusion about the correspondence of creamy-shaken candies with chia seeds to the regulated storage terms by the quality parameters of the lipid complex and by the organoleptic characteristics. But the presented studies don't consider changes that take place at storage with other quality parameters of creamy-shaken candies with chia seeds (humidity, acidity, strength, microbiological safety) that is a weak side of the presented materials. The authors plan to continue the researches in this direction for developing the obtained results.

\section{References}

[1] Kaletnik, H., Lutsiak, V., Melnichuk, O., Dovhan, Y., Malicki, M. (2019). Organizational basis of the development of innovative functional food products by the Ukrainian enterprises of deep walnut processing. Ukrainian Food Journal, 8, 1, 169-180. Available at: http://socrates.vsau.org/repository/getfile.php/20062.pdf

[2] Lesnikova, N. A., Tseeb, O. V., Lavrova, L. Yu. (2013). K voprosu obogascheniya konditerskih izdeliy. Konditerskoe i hlebopekarskoe proizvodstvo, 7-8, 44-45.

[3] Manzhesov, V. I., Truhman, S. V., Kurchaeva, E. E. (2010). Rape seed processing in the technology of dough confectionery. Konditerskoe proizvodstvo, 6, 9-10.

[4] Kravchenko, M., Yaroshenko, N. (2017). Study into effect of plant supplements on the quality indicators of gingerbread and similar spice-cakes. Eastern-European Journal of Enterprise Technologies, 5 (11 (89)), 45-54. doi: https://doi.org/10.15587/17294061.2017.110168

[5] Kravchenko, M., Tkachenko, L., Mihailik, V. (2016). Technology of shortbread cookies with oilseed meal. Tovary i rynky, 2, 138-147.

[6] Shydakova-Kameniuka, O. H., Fomina, I. M., Lysiuk, H. M. (2005). Vplyv yadra nasinnia soniashnyku na fizychni vlastyvosti pisochnoho pechyva. Naukovi pratsi Natsionalnoho universytetu kharchovykh tekhnolohii, 16, 108-110.

[7] Paschenko, L. P., Koval', L. A., Paschenko, V. L. (2006). Pechen'e iz ovsyanoy muki s primeneniem semyan maslichnogo l'na. Modern high technologies, 6, 54-55.

[8] Gaysina, V. A., Kozubaeva, L. A., Kuz'mina, S. S. (2017). Pischevaya tsennost' sdobnogo pechen'ya s podsolnechnoy mukoy. Polzunovskiy vestnik, 2, 19-22.

[9] Bochkarev, S., Papchenko, V., Matveeva, T., Belinska, A., Rudniev, V. (2016). Development of the protein-fatty base of the sugar confectionery for nutrition of the sportsmen. Technology Audit and Production Reserves, 5 (3 (31)), 58-64. doi: https:// doi.org/10.15587/2312-8372.2016.81142

[10] Kyrpichenkova, O. M., Matyiashchuk, O. V., Bozhko, O. C. (2016). Belkovosoderzhaschego use of plant raw materials to improve the quality of water ice. Visnyk Kharkivskoho natsionalnoho tekhnichnoho universytetu silskoho hospodarstva imeni Petra Vasylenka, 179, 181-188.

[11] Shidakova-Kamenyuka, E., Shkliaiev, O., Stepankova, G. (2019). The effect of chia s eeds on qualitative characteristics and chemical composition of cream-whipped candies. Prohresyvni tekhnika ta tekhnolohiya kharchovykh vyrobnytstv, restorannoho hospodarstva ta torhivli, 1 (29), 185-199.

[12] Marcinek, K., Krejpcio, Z. (2017). Chia seeds (Salvia hispanica): health promoting properties and therapeutic applications a review. Roczniki Państwowego Zakładu Higieny, 68 (2), 123-129. Available at: https://www.researchgate.net/publication/317903496_Chia_seeds_Salvia_hispanica_health_promoting_properties_and_therapeutic_applications_-_a_review 
[13] Ayerza, R., Coates, W. (2011). Protein content, oil content and fatty acid profiles as potential criteria to determine the origin of commercially grown chia (Salvia hispanica L.). Industrial Crops and Products, 34 (2), 1366-1371. doi: https:/doi.org/10.1016/ j.indcrop.2010.12.007

[14] Mirzoev, A. M. (2015). Enzymatic processes during storage and processing of oilseeds in the production of vegetable oils. Tehniko-tehnologicheskie problemy servisa, 2 (32), 31-36.

[15] Wrolstad, R. E., Acree, T. E., Decker, E. A., Penner, M. H., Reid, D. S., Schwartz, S. J. et. al. (2004). Handbook of food analytical chemistry. John Wiley \& Sons. doi: https://doi.org/10.1002/0471709085

[16] Rodionova, N. S., Alekseeva, T. V., Popov, E. S., Kalgina, Y. O., Natatova, A. A. (2019). Hygiene aspects and prospects for the domestic production of products of deep processing of wheat germ. Hygiene and Sanitation, 95 (1), 74-79. doi: https:// doi.org/10.18821/0016-9900-2016-95-1-74-79

[17] AOAC. Official Methods of Analysis. Association of Official Analytical Chemists (1990). Washington.

[18] Gorodyska, O., Grevtseva, N., Samokhvalova, O., Gubsky, S., Gavrish, T., Denisenko, S., Grigorenko, A. (2018). Influence of grape seeds powder on preservation of fats in confectionary glaze. Eastern-European Journal of Enterprise Technologies, 6 (11 (96)), 36-43. doi: https://doi.org/10.15587/1729-4061.2018.147760

[19] Lobanov, V. G., Frantseva, T. P., Il'chishina, N. V., Gamanchenko, A. I. (2008). Fermentativniy gidroliz lipidov semyan sortovogo i gibridnogo podsolnechnika pri hranenii. Izvestiya vysshih uchebnyh zavedeniy. Pischevaya tehnologiya, 4, 10-14.

[20] Medvedkov, E. B., Jingilbayev, S. S., Baybolova, L. K., Admayeva, A. M., Kizatova, M. E. (2015). Extraction of oil from seeds of sesame using pressing with preliminary gentle heat treatment. Privolzhskiy nauchniy vestnik, 1 (41), 39-44.

[21] Oliveira-Alves, S. C., Vendramini-Costa, D. B., Betim Cazarin, C. B., Maróstica Júnior, M. R., Borges Ferreira, J. P., Silva, A. B. et. al. (2017). Characterization of phenolic compounds in chia (Salvia hispanica L.) seeds, fiber flour and oil. Food Chemistry, 232, 295-305. doi: https://doi.org/10.1016/j.foodchem.2017.04.002

[22] Lavová, B., Kačmárová, K., Socha, P., Urminská, D. (2016). Characterization of protein fractions and antioxidant activity of Chia seeds (Salvia hispanica L.). Potravinarstvo, 10 (1). doi: https://doi.org/10.5219/563 